\title{
ENTRE CÃES E CADELAS: A HELENA DA ILÍADA
}

Clara Lacerda Crepaldi $\star$ Universidade de São Paulo

\begin{abstract}
In this paper we examine Helen's character in the Iliad by focusing on her self-characterization as a $\operatorname{dog}(\kappa u ́ \omega v)$ and dog-

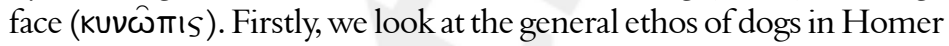
and then we consider the meanings of dog metaphors applied to other characters throughout the Iliad and the Odyssey. By doing this, we conclude that Helen's uses of dog-insults are paradoxically related

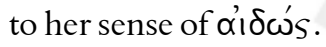

KEYWORDS: Helen; Iliad; Homer; dogs; aidós.

ob variadas formas, o mito diz que a expedição grega a Troia tinha por objetivo recuperar Helena, a espartana, que havia sido roubada de seu marido e de seu palácio pelo troiano Páris. Roubada, como coisa que se rouba, porque antes de tudo Helena é artigo de alto valor simbólico, objeto de disputa, prenda de guerra ( $\left.\gamma^{\varepsilon} \rho \alpha s\right)$ e dádiva ( $\left.\delta \omega \hat{\omega} \rho \circ\right)$ da deusa Afrodite oferecida ao troiano Páris. Por Estesícoro e Eurípides, sabemos que, na Grécia arcaica e clássica, já havia uma vertente do mito que radicalizara esse valor simbólico da Helena de Troia a ponto de transformá-la em mero espectro, um eídolon enganador.

Em Homero, porém, a história não fica por aí. Como quase tudo na Ilíada e na Odisseia, a Helena é um personagem complexo, que, além de possuir esse valor simbólico, também aparece como um sujeito com vida interior própria e com poderes incomuns não só a outras mulheres em condição semelhantes, mas também a todos os outros personagens humanos das epopeias homéricas. Sobretudo na situação de guerra da Ilíada, Helena demonstra profunda consciência de si e de suas

^ claracrepaldi@usp.br 
responsabilidades e é até mesmo capaz de vislumbrar o alcance de sua história nas futuras canções dos aedos. ${ }^{1}$ Se a Helena de Homero não é só aparência, um mero eídolon formado do éter, ${ }^{2}$ também é certo que seu kléos extrapola a sua própria pessoa num prenúncio do que será a Helena fantasmagórica de Estesícoro ou Eurípides.

As atitudes em relação a Helena variam a cada passo. Bem tratada pelos troianos e compreendida até mesmo por Penélope, ${ }^{3}$ Helena tem em si mesma sua maior acusadora. Particularmente marcante é o uso

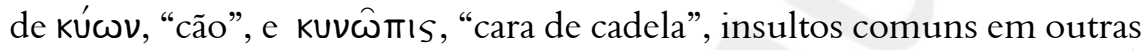
partes da Ilíada e da Odisseia, mas somente autodirecionados por Helena. ${ }^{4}$ Para entender melhor o significado desse tipo de insulto e, em especial, sua aplicação a Helena, examino a seguir a apresentação geral da figura do cão ao longo da Ilíada e da Odisseia e também o uso metafórico de Kú $\omega \nu$ e seus derivados para caracterizar outros personagens (em sentido negativo ou não). Voltarei, por fim, a Helena, seguindo o rastro de suas

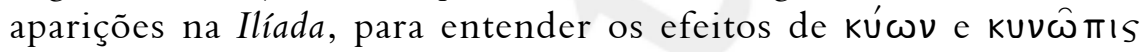
autodirecionados.

\section{Cães propriamente ditos}

Já no proêmio da Ilíada, somos apresentados a uma função homérica do cão das mais detestáveis: a de carniceiro (Il. 1.1-5). ${ }^{5}$ Para um guerreiro que eventualmente morresse no campo de batalha, havia sempre a ameaça de se tornar repasto para os cães (e.g. Il. 2.393, 15.351 e 22. 339). E com o cadáver insepulto, ultrajado, uma psyché de um herói nem mesmo conseguiria acesso ao Hades, tivesse sido ele bravo ou

\footnotetext{
${ }^{1}$ Il. 6.357-8: Sobre nósfez Zeus abater um destino doloroso, para que no futur/ sejamos tema de canto para homens ainda por nascer (tradução de Frederico Lourenço).

${ }^{2}$ E. Hel. 584.

${ }^{3} \mathrm{Na}$ cena de reconhecimento de Penélope e Ulisses, a esposa do herói justifica seu excesso de zelo dizendo que nem mesmo Helena teria dormido com um estrangeiro se soubesse que os gregos empregariam a força para resgatá-la, porque fora um deus

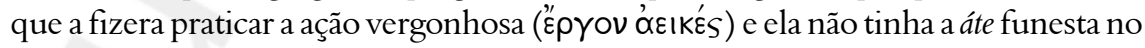
coração (Od.23.218-224).

${ }^{4}$ Observação feita por Margaret Graver (Dog-Helen and homeric insult. Classical Antiquity. Berkeley, vol. XIV, n. 1, p. 41-61, 1995 - disponível em <http:// www.jstor.org/stable/25000142>. Acesso em 24 mar. 2011).

${ }^{5}$ Cães carniceiros também são comuns na Odisseia, e.g. Od. 3.259; 14.134; 18.87; $21.363 ; 22.476$.
} 
covarde, nobre ou vil. Essa selvageria é o primeiro e um dos mais evidentes traços do ethos canino em Homero e pode ser relacionada a uma ơv $\alpha i ́ \delta \varepsilon ı \alpha,{ }^{6}$ frequentemente atribuída aos cães e usada como explicação para epítetos derivados. ${ }^{7}$

O campo de guerra onde se passa a maior parte da Ilíada não é exatamente o cenário mais propício para cães, e portanto, a maior parte dos cachorros dessa epopeia aparece em símiles ou metáforas. No caso dos símiles, o comum é que cenas de combate humano sejam comparadas a atividades de caça com cães (e.g. Il. 3.23-26 e 11.414-418), pelo que ficamos sabendo que esse cão arcaico é sobretudo um caçador.

Outra função de utilidade do cão é a guarda, que aparece em símile (Il. 10.183-186) ou na figura concreta dos cães de guarda de Alcínoo (Od. 7.91-94), Príamo (Il. 22.66-71) e Eumeu (Od. 14.21-22). A esses se juntariam, talvez, Cérbero, o cão odioso de Hades (Il. 8.368), e também os leões e lobos enfeitiçados de Circe, que abanam a cauda como cães interesseiros (Od. 10.212-218). No caso dos cães de Príamo, é importante notar que esses mesmos cachorros que o rei troiano diz ter criado à sua mesa são aqueles que vão profanar o seu cadáver quando Troia tiver caído. A passagem indica que, mesmo domesticado, esse cão homérico permanece a um passo da selvageria carniceira, ainda longe de ser um dócil animal de estimação. ${ }^{8}$

$\mathrm{Na}$ Odisseia, em particular, essa utilidade do cão é destacada e até posta em contraste com uma criação de cães apenas para o luxo de seus

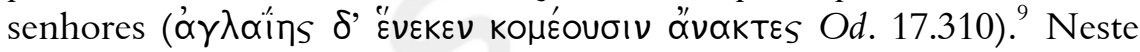
binômio cão de guarda x cão de exposição, o velho cão de Ulisses, outrora um exímio caçador (Od. 17.316-317), e também os cães de guarda de

\footnotetext{
${ }^{6}$ Cf. Corrêa, P. C. Um bestiário arcaico. Fábulas e imagens de animais na poesia de Arquíloco. Campinas: UNICAMP, 2010, p. 401.

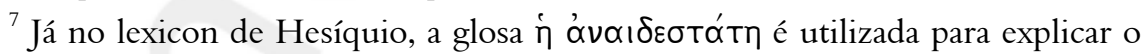

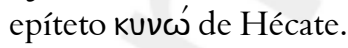

${ }^{8}$ Cf. Kitchell, K. F. Man's best friend? The changing role of the dog in Greek society. In: Frizell, B. S. Pecus. Man and animal in Antiquity. Proceedings of the Conference at the Swedish Institute in Rome, September 9-12. Rome: The Swedish Institute, 2002, p. 177-178 - disponível em < http://www.isvroma.it/public/pecus/kitchell.pdf>. Acesso em 3 fev. 2009.

${ }^{9}$ Sobre a relevância desse contraste no contexto da cena de Argos, veja-se Scodel (Odysseus' dog and the productive household. Hermes. Stuttgart, vol. CXXXIII, n. 4, p. 401-408, 2005-disponível em < http://www.jstor.org/stable/4477672>. Acesso em 26 abr. 2011).
} 
Eumeu serviriam para sublinhar a diferença entre a produtividade da casa e do reino de Ulisses' e a vã ostentação dos pretendentes. ${ }^{10}$ Mas justamente porque essa diferenciação entre esses dois tipos de cão está inserida no discurso de Ulisses e na economia própria da Odisseia, marcada por essa diferença de caráter entre o legítimo soberano de Ítaca e aqueles que querem tomar o seu lugar, talvez ela não mereça muita consideração.

Ainda sobre os cães de guarda de Eumeu, vale a pena notar que esses cães não simplesmente atacam quem quer que se aproxime, como no caso da chegada de Odisseu (Od. 14.21), mas também saúdam amigavelmente os conhecidos, como no caso da aparição de Telêmaco (Od. 16.4-10), e, mais surpreendentemente, têm a intrigante capacidade de perceber uma presença divina, que somente Odisseu entre os homens é capaz de enxergar (Od. 16.162-163).

Perto do final da Ilíada, no funeral de Pátroclo (Il.23.164-183), Aquiles degola dois dos nove cães criados por Pátroclo à sua mesa, ${ }^{11}$ para acrescentálos à pira de seu dono - pira que, aliás, já contava com ovelhas, bois, mel, azeite, quatro cavalos e doze prisioneiros troianos. A própria presença desses tantos cães no acampamento de guerra soa um tanto anômala, mas me parece que a tentativa de racionalizar demais essa presença seja superinterpretar um detalhe de uma narrativa, que, de resto, não é realista. Richardson $^{12}$ nota que esse sacrifício de cães, cavalos e homens é único em Homero e parece sinalizar a magnitude do sofrimento de Aquiles pela perda de Pátroclo. Mas se o sacrifício dos troianos tem a finalidade óbvia explícita no discurso de Aquiles - de vingar o assassinato de Pátroclo, não fica tão clara assim qual seria a funcionalidade do sacrifício dos cães e dos cavalos. A ideia, manifesta em Luciano (De luctu, 14), de que esses animais poderiam ser aproveitados pelo morto no Hades também não resolve a questão de qual seria exatamente essa utilidade: companhia, guarda, caça? Em todo caso, não há motivo nenhum para acreditar que esses cães seriam

\footnotetext{
${ }^{10}$ Cf. Scodel, op. cit.

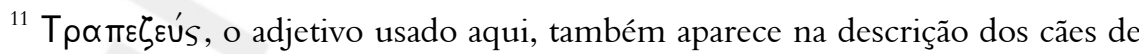
Príamo e na caracterização que Odisseu faz do "cão de banquetes" (expressão de Carlos Alberto Nunes), criado apenas para luxo de seus senhores. No contexto dos cães de Pátroclo e Príamo, a expressão parece indicar apreço especial a esses animais

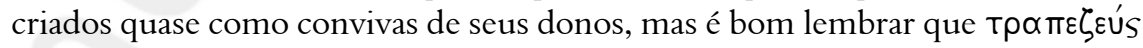
também pode ser usado para caracterizar um parasita ou conviva indesejado

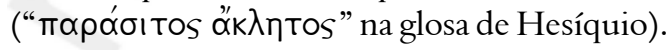

${ }^{12}$ Cf. Richardson, N. The "Iliad": a commentary. Vol. VI (books 21-24). Cambridge: Cambridge University Press, 1993, p. 188-189.
} 
"carinhosamente assassinados" por Aquiles para ocupar "o lugar de mais alta honra" na pira de Pátroclo, como quer Scott. ${ }^{13}$

De quase todos esses cães mencionados até aqui não é possível perceber nenhuma manifestação clara de afeto aos humanos, nem por parte dos próprios cães, nem por parte de seus donos. A exceção é Argos.

Nas incontáveis glosas à cena de reconhecimento de Ulisses e seu cão, os comentadores já identificaram diversos estratos de interpretação: antes de qualquer coisa, o pathos da condição de Argos e sua morte; sua lealdade; a posição desse episódio na série de reconhecimentos do final da Odisseia; a identificação do estado do cão com o estado da casa e com o estado do dono; o prenúncio de acontecimentos ainda por vir. ${ }^{14}$ Para os fins dessa investigação, o que cumpre observar é exatamente essa relação de afeto, amizade e lealdade entre Ulisses e seu cão. Velho e maltratado, Argos reconhece Ulisses sem ajuda de nenhum sinal - ele é o único de Ítaca a fazê-lo - e usa suas últimas forças para saudar o seu dono antes de morrer. Odisseu, de sua parte, pode apenas esconder uma lágrima furtiva para não revelar sua verdadeira identidade ao porqueiro Eumeu.

\section{O homem-cão (e a mulher-cadela)}

A cena de Argos inicia uma importante identificação de Ulisses com o cão, que como o dono reunia dotes de rapidez ( $\propto \propto \chi \cup T \hat{\tau} \propto)$, força

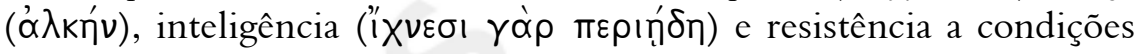
adversas. Essa identificação vai ser desenvolvida mais tarde na descrição

\footnotetext{
${ }^{13}$ Cf. Scott, J. A. Dogs in Homer. The classical weekly. Philadelphia, vol. XLI, n. 15, p. 228, 1948 - disponível em < http://www.jstor.org/stable/4342451>. Acesso em 13 jun. 2011. O comentador narra o trecho da seguinte forma: Here it is told how under the guidance of Achilles a pile of wood one hundred feet square was erected, sheep in great numbers were slain, cattle were added, then four fine horses were put on the pyre, and finally uppermost and in the place of greatest distinction two dogs, table companions of Achilles, tenderly slain by the hero himself, were offered in honor of Patroclus (grifos meus).

${ }^{14} \mathrm{Cf}$. Beck, W. Dogs, dwellings, and masters. Ensemble and symbol in the "Odyssey". Hermes. Stuttgart, vol. CXIX, p. 158-167, 1991 - disponível em <http:// www.jstor.org/stable/4476813 > . Acesso em 13 jun. 2011; Jong, I. J. F. Narratological commentary on the "Odyssey". New York: Cambridge University Press, 2011, p. 421; Reece, S. The stranger's welcome. Oral theory and the aesthetics of the Homeric hospitality scene. Ann Arbor: University of Michigan, 1993, p. 170; Rose, G. P. Odysseus' barking heart. Transactions of the American philological association. Baltimore, vol. CIX, p. 215-230, 1979 - disponível em <http://www.jstor.org/stable/284059>. Acesso em 17 jun. 2011.
} 
do broche que Ulisses usava quando partiu de Ítaca (Od. 19.226-231) e no símile da cadela que late aos estranhos para defender os seus filhotes (Od. 20.13-16). No primeiro desses trechos, lê-se o seguinte:
Manto purpúreo, de lã, envergava o divino Odisseu, muito amplo e cômodo, preso por áureo colchete vistoso, de duplo encaixe, com jóia admirável na parte da frente: um cão sustinha nas patas da frente uma corça listrada, que estrebuchava. Ante o grupo nós todos sentíamos pasmo: como, sendo ouro, podia o mastim prear a corça e esganá-la? E como a corça tentava fugir, a espernear tanto e tanto ${ }^{15}$

(Od. 19.225-231)

Rose analisa a figura desse broche, ${ }^{16}$ comparando-o a três símiles que contêm cenas semelhantes na Ilíada, ${ }^{17}$ e conclui que a impotência da corça perante a força do cão antecipa a impotência dos pretendentes diante da fúria da vingança de Ulisses. Também apoia essa interpretação um outro símile que aparece mais cedo na Odisseia, quando em Esparta (Od. 4.335-340) Menelau diz o seguinte sobre os pretendentes:

Pois é possível que tais indivíduos, sem força nenhuma, queiram deitar-se no leito de um homem como esse, tão forte!

Bem como quando, no espesso do bosque, onde um leão formidando leito fizera, uma corça aí deixara seus tenros filhinhos, para sair a pastar pelos cerros e vales ervosos;

mas o leão para o pouso retorna, passados momentos, e logo, ali, a ambos eles com morte horrorosa extermina: do mesmo modo Odisseu a eles todos dará morte horrível.

(Od.4.333-340)

O trecho reapresenta a fragilidade e impotência dos pretendentescorças, diante, dessa vez, de um Ulisses-leão. Esse símile ainda é repetido mais uma vez por Telêmaco, já em Ítaca (Od. 17.126-131).

\footnotetext{
${ }^{15}$ Todas as citações da Odisseia provém de Homero. Odisseia. Tradução de Carlos Alberto Nunes. Rio de Janeiro: Editora Três, 1974.

${ }^{16}$ Cf. Rose, op. cit., p. 244 ss.

17 10.360-362: Odisseu e Diomedes perseguem Dólon, como cães atrás de uma corça ou lebre; 15.579-581: Antíloco se lança sobre o cadáver de Melanipo como um cão sobre um gamo ferido; 22.189-192: Aquiles persegue Heitor ao redor das muralhas de Troia como um cão no rastro de um gamo.
} 
O Ulisses-cão reaparece mais tarde em um símile do canto XX (v. 13-16). Sem conseguir dormir, porque planeja males para os pretendentes, Ulisses ouve o riso das criadas traidoras que costumam se unir aos seus inimigos e, enfurecido, pensa em matá-las naquele instante. Nesse momento, o seu coração late no peito,

como faz a cachorra que à roda dos filhos

salta furiosa, ladrando, ao sentir gente estranha que chega:

o coração, deste modo, bramia, ante aquela vileza.

(Od.20.13-16)

Dessa vez, a característica canina que Ulisses assume é a guarda aguerrida de sua casa e dos seus. Para arrematar, a continuação do trecho

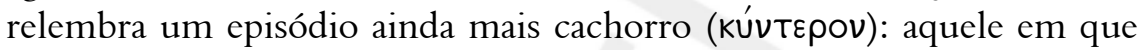
o Ciclope devorou os companheiros de Ulisses, episódio que ecoa no símile da cadela, porque no canto IX (v. 289), Polifemo arrebata dois dos

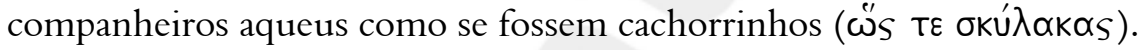

Nessa sequência que inclui o encontro com Argos, a descrição do broche e o símile da cadela, o personagem central da Odisseia assimila características caninas com valor positivo. Mas não é por isso que chamar alguém de cão deixa de ser insulto na Odisseia. No canto XVII, apenas um pouco antes do encontro com Argos, Eumeu e Ulisses passam pelo pastor Melântio, que, sem reconhecer o amo, o injuria, agride e chama

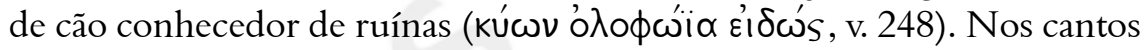
seguintes, a cadela será a irmã de Melântio, a serva Melanto, que por também abusar do mendigo Odisseu é chamada de cadela pelo próprio herói

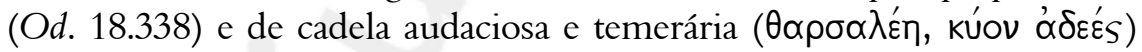
por Penélope (Od. 19.91). No canto XIX, as servas de um modo geral são chamadas de cadelas mais duas vezes, uma por Penélope (v. 154) e outra por Euricleia (v. 372).

Assim como seus pares femininos, os pretendentes também são chamados de cães por Odisseu, no momento de sua vingança (Od. 22.35). Nessa apresentação das servas e dos pretendentes como cães, as características caninas prevalecentes são a audácia, temeridade, falta de tento ou de

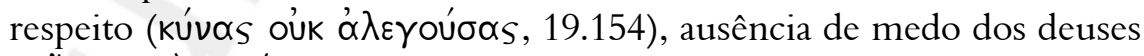

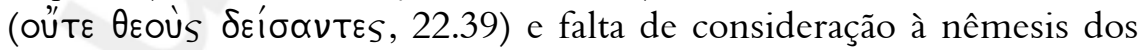
homens (22.40). Esse retrato geral condiz com a definição frequente do

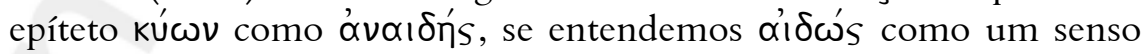
de respeito às normas da comunidade, acompanhado de um temor às opiniões alheias. Às vezes, o próprio contexto de uso dos epítetos caninos apoia essa interpretação. No canto primeiro da Ilíada, o epíteto 


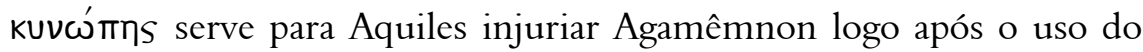
vocativo $\mu \varepsilon^{\prime} \gamma^{\prime}$ óvoı $\delta_{\varepsilon}^{\prime} s$ (v. 158-159), assim como na embaixada do canto

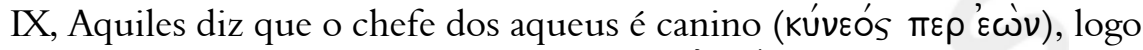

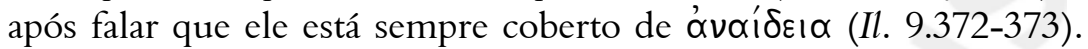

No campo de guerra, kúwv é usado para insultar adversários de um lado e de outro. Assim como Menelau chama os troianos de cadelas

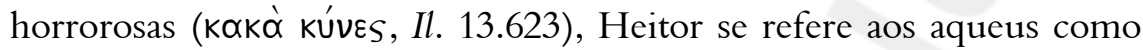
cães (8.527) e Teucro se queixa da dificuldade de acertar o cão raivoso

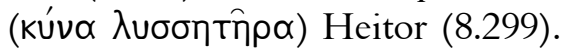

Heitor, aliás, tem momentos caninos bem marcados ao longo da epopeia. Mais tarde, no canto VIII, um símile diz:

Tal como o galgo que, na perseguição com patas velozes, ao javali ou ao leão toca por trás no flanco ou nas nádegas, e está atento ao momento em que a presa se desvia assim Heitor pressionava os Aqueus de longos cabelos, matando quem ficava pra trás. Eles fugiam, desbaratados. ${ }^{18}$

(Il. 8.338-342)

Nesse momento, a excelência guerreira de Heitor é ilustrada pela imagem do cão caçador. Compare-se isso ao passo em que Diomedes chama Heitor de cão, depois de este escapar da morte às suas mãos (11.362) ${ }^{19}$ e também ao uso anômalo de kúvtatov no episódio da Doloneia, quando Diomedes pensa que coisa mais cachorra ele deve fazer entre as façanhas possíveis no acampamento dos trácios (10.503-506). Se na fala de Diomedes a Heitor não é possível afirmar que o epíteto kúwv contenha alguma alusão à areté guerreira do troiano, o sentido de kúvtatov na Doloneia apoia uma possível indicação das proezas de Heitor na fala de Teucro mencionada anteriormente (8.299). Essa ocorrência de kúvTaTov, aliás, é normalmente considerada como a única metáfora canina de Homero

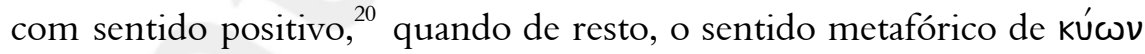
é sempre pejorativo, apesar dos símiles com cães, às vezes, não o serem.

De todo modo, o momento canino mais marcante de Heitor é quando, um pouco antes de morrer, ele suplica a Aquiles que não lhe

\footnotetext{
${ }^{18}$ Para as citações da Ilíada, utilizo a tradução de Frederico Lourenço (Homero. Ilíada. Tradução de Frederico Lourenço. Lisboa: Cotovia, 2010).

${ }^{19}$ Todo o bloco de versos 362-7 será repetido por Aquiles no canto XX, v. 449-454. ${ }^{20}$ Graver (op. cit., p. 47) discorda dessa leitura e argumenta que kúvтðтov nesse passo é um julgamento anômalo do poeta-narrador a uma má ação de Diomedes.
} 
deixe ser devorado pelos cães, mas restitua o seu cadáver à sua casa, mediante o devido resgate (Il. 22.338-343). Aquiles, irado, não apenas nega o pedido, mas também o chama de cão e diz até que gostaria de ter força e ânimo para lhe cortar a carne e comê-la crua (Il. 22. 345-354). A fala é irônica: Aquiles chama Heitor de cão, mas é ele mesmo o

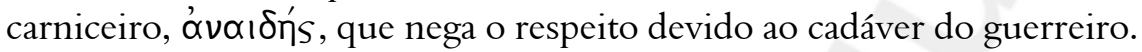

Os epítetos caninos também servem para injuriar as deusas Afrodite (Od. 8.319), Ártemis (Il. 21.481) e Hera (Il. 8.423 e 18.396). Desses, o caso

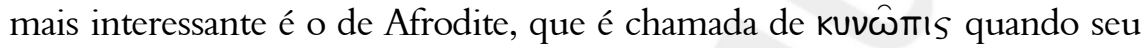
marido Hefesto a flagra na cama com Ares (Od. 8.306-320). Os comentadores geralmente mencionam a lubricidade do cão para explicar o uso de epítetos derivados de kú $\omega v$ aplicados a mulheres (deusas ou mortais). Mas me parece que no contexto homérico esse episódio é o único em que a qualidade de cão de uma mulher pode ser diretamente relacionada à sua licenciosidade, e mesmo aqui esse não é o aspecto principal. ${ }^{21}$ Até mesmo no caso emblemático de Clitemnestra, mulher que trai o marido, como a leal Penélope nunca trairá Odisseu, a 'cadelice' da personagem não é associada à luxúria. A fala de Agamêmnon no Hades, ao contrário, sublinha muito mais a traição em termos do assassinato do marido - essa sim obra vergonhosa da esposa mais cadela (Od. 11.405-434).

\section{Enfim, Helena}

A esse depoimento de Agamêmnon no Hades, Ulisses vai responder que certamente Zeus infligiu duras penas à descendência de Atreu por meio dos conselhos de suas mulheres, já que além de Clitemnestra traidora, houve também Helena pela qual muitos dos aqueus morreram (Od. 11.436-439). É assim também, como motivo da destruição de muitos gregos, que Helena é mencionada pela primeira vez na Ilíada, na fala de Hera (Il. 161-162).

Antes de a própria Helena entrar em cena na Ilíada, seu nome é evocado três vezes. Primeiro na fala de Hera referida acima, depois no discurso de Nestor, que defende a permanência dos Aqueus na guerra troiana:

\footnotetext{
${ }^{21}$ Lefkowitz, por exemplo, argumenta que a misoginia grega está mais relacionada a uma suscetibilidade a paixões destrutivas do que ao próprio desejo sexual (Women in Greek myth. Bristol: Classical Press, 1986, p. 112-126). Aqui a acusação de Hefesto

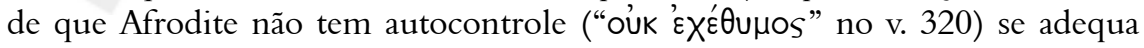
perfeitamente a essa interpretação.
} 


\section{(...)}

Por conseguinte, que ninguém se apresse a regressar a casa,

Antes que ao lado da mulher de algum Troiano tenha dormido,

Vingando assim os estrebuchamentos e lamentações de Helena.

(Il.2.354-356)

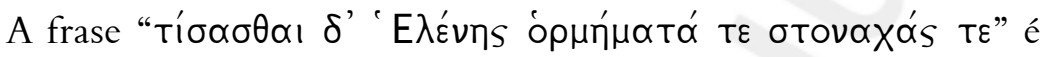
repetida com alteração mínima no catálogo das naus, quando de Menelau é dito que ele se movimentava entre os companheiros incitando-os à guerra, porque desejava no coração "vingar os estrebuchamentos e lamentações de Helena” (Il. 2.588-590). O significado da frase é ambíguo, porque gramaticalmente a expressão tanto pode se referir aos estrebuchamentos e lamentações de Helena, quanto aos estrebuchamentos e lamentações dos gregos causados por Helena. Aristarco defendia a segunda leitura, rejeitando a visão separatista de que Helena seria retratada de maneiras distintas nas duas epopeias homéricas, sendo raptada à força na Ilíada e fugindo voluntariamente na Odisseia. De resto, os comentadores oscilam entre as duas interpretações conforme sejam suas ideias sobre o caráter de Helena na Ilíada. ${ }^{22}$

De todo o modo, a controvérsia de Helena ter ido a Troia à força ou por vontade própria nunca é colocada como questão central em Homero. Em lugar disso, independentemente de ela ter fugido com

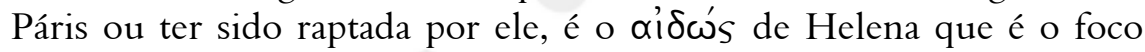
principal da apresentação da personagem em Homero. E daí decorre o

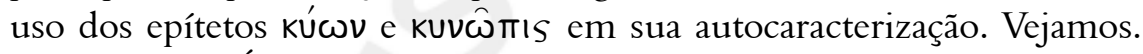

Quando Íris se aproxima de Helena para chamá-la, encontra-a tecendo uma grande e luxuosa tapeçaria, na qual ela bordava as contendas que troianos e aqueus sofriam por sua causa (Il. 3.125-129). Por comum que seja a atividade tecelã para mulheres em Homero, ${ }^{23}$ a autorreferen-cialidade do bordado de Helena eleva a sua ocupação a um nível mais alto. Com efeito, essa imortalização dos feitos da guerra por meio da tapeçaria remete à

${ }^{22}$ Roisman (Helen in the "Iliad"; "causa belli" and victim of war: from silent weaver to public speaker. American journal of philology. Baltimore, vol. CXXVII, p. 3, 2006 - disponível em < http://www.jstor.org/stable/3804922> . Acesso em 26 jan. 2010) é pró-Helena, Yamagata (Homeric morality. Leiden: Brill, 1993, p. 22) e Kirk [The "Iliad": a commentary. Vol. I (books 1-4). Cambridge: Canbridge University Press, 1985, p. 153 e 214] são contra.

${ }^{23}$ Andrômaca (Il. 6.490), Penélope (Od. 2.94), Circe (Od. 10.221), as ninfas de Ítaca (Od. 13.107), a deusa Atena (Il. 8.385 e 14.178) e a própria Helena, em outras circunstâncias (Od.15.123), também se ocupam do tear. 
própria atividade do aedo, de modo semelhante ao canto metalinguístico de Aquiles no canto IX. Em sua primeira aparição, Helena é uma personagem com poder criativo e com capacidade de entender, articular e quiçá escrever a sua própria história. E fazendo isso, Helena também começa a assumir para si a sua parcela de responsabilidade na guerra.

O segundo aspecto aparente nesse ponto da narrativa é o pathos da saudade que Helena sente de sua casa legítima, ainda que essa saudade lhe seja lançada no peito pela deusa Íris. Helena, de fato, chora de saudades do marido, da cidade e dos progenitores, enquanto se põe a caminho das Portas Esqueias para assistir ao duelo de Páris e Menelau. A próxima cena da admiração dos anciãos ante a beleza de Helena (3.154-160) eleva a nobreza da personagem ao mais alto nível, pois nem esses sábios, que já superaram a idade das tentações sensuais, são capazes de dizer que o longo sofrimento de troianos e aqueus por uma mulher como Helena seja motivo de indignação ( $v \varepsilon ́ \mu \varepsilon \sigma ı s)$.

Não são somente os anciãos que demonstram especial deferência à Helena, mas também o rei Príamo a trata como "querida filha" (Il. 3.162 e 192) e lhe diz que a culpa da guerra é dos deuses e não dela. Helena responde a Príamo em tom igualmente gentil e afetuoso:
Venerando és tu para mim, querido sogro, e terrível: quem me dera ter tido o prazer da morte malévola, antes de para aqui vir com o teu filho, deixando o tálamo, os parentes, a minha filha amada e a agradável companhia das que tinham a minha idade: mas isso não pôde acontecer. E é por isso que o choro me faz definhar. Mas responder-te-ei àquilo que me perguntas. Este é o Atrida, Agamémnon de vasto poder, que é um rei excelente e um forte lanceiro. Era cunhado da cadela que sou; se é que foi mesmo.

(Il.3.172-180)

Tratando-o por "querido sogro", Helena diz que Príamo é a’ı́ôos

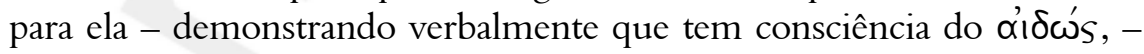
e, em seguida, avalia pela primeira vez sua própria situação. Entre o lamento por não ter morrido antes de ir a Troia e o primeiro uso do

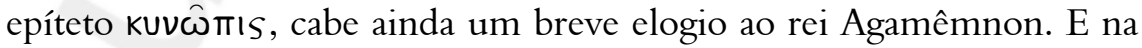
Teicoscopia, Helena também nota a ausência de seus irmãos Castor e Polux e supõe que eles não tenham comparecido por temerem vergonhosos insultos a seu respeito (3.236-242). Até esse ponto, essas primeiras manifestações de Helena apresentam a personagem como alguém que tem profunda consciência e grande vergonha de sua responsabilidade 
nos sofrimentos da guerra, ainda que essa responsabilidade, pelo ponto de vista da própria personagem, pareça exagerada, se comparada aos julgamentos de outros, incluindo os sábios anciãos troianos.

As cenas subsequentes amplificam ainda mais o heroísmo de Helena. Ante o ultraje de se unir ao perdedor Páris, Helena ousa desafiar a própria deusa Afrodite, que ela é capaz de reconhecer apesar do disfarce (3.399412). Afrodite tenta atrair Helena descrevendo os encantos do belíssimo Alexandre, que acaba de voltar do combate como se tivesse voltado de uma dança (3.390-394), mas a espartana não apenas resiste a essa tentação sensual, como manda a própria Afrodite ir ao encontro de Páris para ser sua esposa ou escrava, já que a deusa gosta tanto dele. Como observa Roisman, ${ }^{24}$ a sugestão é ainda mais ofensiva não só porque reduz a deusa ao status de escrava, mas porque a faz escrava de suas próprias paixões de um modo que a própria Helena não o é. A espartana encerra seu discurso dizendo que não vai voltar para o tálamo de Páris, porque isso seria motivo de indignação ( $(\varepsilon \mu \varepsilon \sigma \sigma \eta T o ́ v)$ e censura por parte das troianas. Mais uma vez, Helena demonstra o zelo apropriado à sua reputação.

Ameaçada por Afrodite, Helena enfim se submete à deusa e vai ao encontro de Páris. Porém não se deita com seu atual cônjuge antes de manifestar o desejo de que ele tivesse morrido às mãos de seu primeiro e mais forte marido. Ao final, ela mesma pede que Páris desista do duelo para que não seja vencido, em uma fala que, às vezes, é entendida como ironia sarcástica, às vezes, como sinal da volatilidade de Helena e da ambiguidade dos seus sentimentos (3.428-436).

Mas a próxima aparição da personagem (6.323ss.) vai confirmar o desprezo que Helena sente pelo atual marido. A Heitor, que censura Páris por estar fora da batalha, Helena diz que, em circunstâncias tão ruins, desejaria, ao menos, ter um homem melhor, e não esse que não tem o juízo perfeito. Dessa vez, Helena se chama de cadela duas vezes e põe a culpa da guerra primeiro nos desígnios dos deuses, depois em sua própria cadelice e na áte de Alexandre (6.344-358).

A cena também demonstra uma afeição de Helena a Heitor, que contrasta com o tratamento que ela dispensa ao próprio marido. Com efeito, se no canto terceiro, Helena foi obrigada por Afrodite a se sentar junto de Páris, dessa vez, é a própria Helena quem chama o cunhado a sentar-se junto de si. Essa afeição é reiterada na prece funerária sobre o cadáver de Heitor (24.762-775), quando Helena reafirma que preferia ter morrido antes de ir a Troia e diz que então já não há quem lhe seja gentil ou amigo em Troia, mas que é desprezada por todos.

${ }^{24}$ Cf. Roisman, op. cit., p. 18. 
Mas apesar de Helena mencionar que Heitor a defendia dos ataques de seus familiares troianos, nas epopeias homéricas, só há duas únicas menções negativas a Helena feitas por outros personagens que não ela mesma, e ambos são gregos. Uma delas aparece no canto XIX da Ilíada, quando Aquiles diz que combate em Troia por causa de Helena horripilante $(\hat{\rho} \mid \gamma \varepsilon \delta \alpha \nu \bar{\eta} s),{ }^{25}$ a outra surge no canto XIV da Odisseia, quando Eumeu preferiria que a raça de Helena fosse extinta antes que seu amo morresse longe da pátria (Od. 14.68-70). Mas em ambas as cenas, tanto Aquiles quanto Eumeu assumem atitudes pessimistas em relação a Helena, quando estão diante de desastres causados pela guerra: a perda de Pátroclo, no primeiro caso, a suposta morte de Ulisses, no segundo. Mais do que criticar a própria Helena, Aquiles e Eumeu lamentam a guerra em si e suas consequências, o que de certo modo dá razão aos lamentos de Helena sobre sua má reputação.

Ao longo da Ilíada, o retrato apresentado da Helena é a de uma mulher, que apesar de cativa e sujeita a várias restrições, inclusive

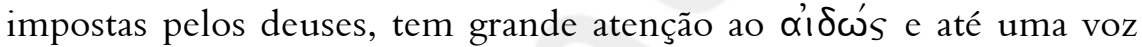
própria para se rebelar diante de ameaças à sua reputação já prejudicada. É nesse quadro que se deve entender o uso paradoxal dos epítetos caninos: justamente porque é a’íoín e respeita as restrições impostas

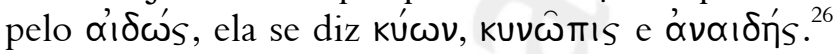

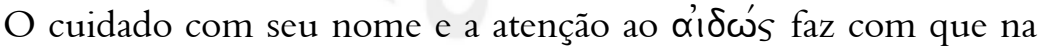
má fama da Helena homérica já esteja prevista a tragédia de uma outra Helena, a de Eurípides, que sofre por males causados unicamente à sua reputação. Mas o comprometimento da Helena da Ilíada é mais contundente: se a Helena da tragédia sofre pela má fama imerecida, a Helena da épica sofre simplesmente pela má fama - e a ela nem interessam questões de merecimento.

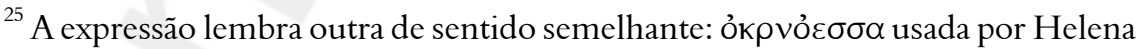
no canto 6 (v. 344).

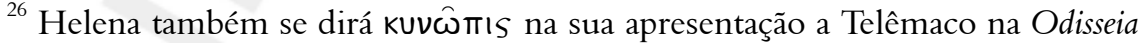
(4.145-6), mas aí o contexto da declaração é complexo, porque aparentemente envolve uma discordância entre Menelau e Helena sobre sua lealdade ao esposo grego em Troia [cf. Olson, D. The stories of Helen and Menelaus ("Odyssey" 4.240-89) and the return of Odysseus. American journal of philology. Baltimore, vol. CX, n. 3, p. 387394, 1989 - disponível em < http://www.jstor.org/pss/295214>. Acesso em 27 nov. 2007/ Austin, N. Helen of Troy and her shameless phantom. Ithaca: Cornell University Press, 1994, p. 81-83].
} 


\section{Referências}

AUSTIN, N. Helen of Troy and her shameless phantom. Ithaca: Cornell University Press, 1994.

BECK, W. Dogs, dwellings, and masters: ensemble and symbol in the "Odyssey". Hermes. Stuttgart, vol. CXIX, p. 158-167, 1991 - disponível em < http:// www.jstor.org/stable/4476813 >. Acesso em 13 jun. 2011.

CORREAA, P. C. Um bestiário arcaico. Fábulas e imagens de animais na poesia de Arquíloco. Campinas: UNICAMP, 2010.

GRAVER, M. Dog-Helen and homeric insult. Classical Antiquity. Berkeley, vol. XIV, n. 1, p. 41-61, 1995-disponível em < http://www.jstor.org/stable/25000142>. Acesso em 24 mar. 2011.

HOMERO. Odisseia. Tradução de Carlos Alberto Nunes. Rio de Janeiro: Editora Três, 1974.

. Ilíada. Tradução de Frederico Lourenço. Lisboa: Cotovia, 2010.

JONG, I. J. F. Narratological commentary on the "Odyssey". New York: Cambridge University Press, 2011.

KIRK, G. S. The "Iliad": a commentary. Vol. I (books 1-4). Cambridge: Canbridge University Press, 1985.

KITCHELL, K. F. Man's best friend? The changing role of the dog in Greek society. In: FRIZELL, B. S. (org.). Pecus. Man and animal in Antiquity. Proceedings of the Conference at the Swedish Institute in Rome, September 9-12. Rome: The Swedish Institute, 2002, p. 177-178 - disponível em < http://www.isvroma.it/public/pecus/ kitchell.pdf>. Acesso em 3 fev. 2009.

LEFKOWITZ, M. Women in Greek myth. Bristol: Classical Press, 1986.

OLSON, D. The stories of Helen and Menelaus ("Odyssey" 4.240-89) and the return of Odysseus. American journal of philology. Baltimore, vol. CX, n. 3, p. 387-394, 1989 - disponível em < http://www.jstor.org/pss/295214>. Acesso em 27 nov. 2007.

REECE, S. The stranger's welcome. Oral theory and the aesthetics of the Homeric hospitality scene. Ann Arbor: University of Michigan, 1993.

RICHARDSON, N. The "Iliad": a commentary. Vol. VI (books 21-24). Cambridge: University Press, 1993.

ROISMAN, H. M. Helen in the "Iliad"; "causa belli" and victim of war: from silent weaver to public speaker. American journal of philology. Baltimore, vol. CXXVII, p. 1-36, 2006 - disponível em < http://www.jstor.org/stable/3804922>. Acesso em 26jan. 2010.

ROSE, G. P. Odysseus' barking heart. Transactions of the American philological association. Baltimore, vol. CIX, p. 215-230, 1979 - disponível em < http://www.jstor.org/stable/ 284059>. Acesso em 17 jun. 2011.

SCODEL, R. Odysseus' dog and the productive household. Hermes. Stuttgart, vol. CXXXIII, n. 4, p. 401-408, 2005 - disponível em < http://www.jstor.org/stable/ 4477672>. Acesso em 26 abr. 2011. 
SCOTT, J. A. Dogs in Homer. The classical weekly. Philadelphia, vol. XLI, n. 15, p. 226-228, 1948 - disponível em < http://www.jstor.org/stable/4342451>. Acesso em 13 jun. 2011.

YAMAGATA, N. Homeric morality. Leiden: Brill, 1993. 